\title{
Risk-based Security Assessment in Distribution Network with the Integration of Photovoltaic
}

\author{
Wanxing Sheng ${ }^{1}$, Keyan $\mathrm{Liu}^{1}$, Yating $\mathrm{Cai}^{2}$ and Songhuai $\mathrm{Du}^{2, \mathrm{a}}$ \\ ${ }^{1}$ China Electric Power Research Institute, Power Distribution Department, 100192, Beijing \\ ${ }^{2}$ China Agricultural University, College of Information and Electrical Engineering, 100083, Beijing
}

\begin{abstract}
With the development of distribution network, distributed generation such as wind and photovoltaic $(\mathrm{PV})$ power will become increasingly prominent in the near future. PV is widely constructed because of advantages it has. However, the volatility and randomness of PV makes it more complex than traditional energy in the security assessment of distribution network. Based on risk theory, considering the randomness of PV, node low voltage risk index and line overload risk index are established in this paper. Also, $\mathrm{K}(\mathrm{N}-1+1)$ principle for distribution network which is developed from traditional (N-1) deterministic principle is applied to reflect the flexible structure of distribution network. IEEE three-feeder example system is utilized to investigate the influence of PV power on the security assessment of distribution network.
\end{abstract}

\section{Introduction}

With the increasing demand for energy, development and utilization of renewable energy have become more and more important. Secure and reliable wind power, PV power and other distributed power ought to be developed to adjust to smart distribution network. PV is widely favoured because of its safety, short construction period, no noise, no pollution and other advantages. However, the output of PV power is influenced by its volatility and uncertainty. These features make it different from the traditional standby power in the reliability and risk assessment [1]. Therefore, it's necessary to study the security assessment based on risk theory of distribution network containing PV power.

Line overload, node low voltage and load points blackout risk indices are established and distribution network risk assessment system are proposed based on utility theory in document [2]. Node low voltage and line overload are selected as risk indices analysing the security of distribution network in the case of different solar access capacity in document [3]. Combined with distribution network reliability index, energy loss rate of accident and customers' loss rate of accident risk indices are established and corrected in the access of distributed power in document [4].

The structure of distribution network varies flexibly. When the component (branch) switches off, branches along the direction of the flow will be completely de-energized and non-fault power failure region occurs. In this case, traditional safety indicators and analysis methods are no longer suitable for

${ }^{a}$ Corresponding author : songhuaidu@cau.edu.cn 
the network [5]. Referring to the conventional (N-1) security criterion used in bulk power network, $\mathrm{K}$ $(\mathrm{N}-1+1)$ principle is proposed for distribution network analysis in document [6], according to the characteristics of structure and operation of the distribution network. The static security based on risk theory is evaluated in the absence of distributed power in document [7].

Based on documents mentioned above, node low voltage index and line overload index are established in this paper to analyse the security of distribution network by combining risk theory and $\mathrm{K}(\mathrm{N}-1+1)$ deterministic principle.

\section{Models for Security Assessment based on Risk Theory}

Risk is a quantization of uncertain factors of the system. Risk index, usually defined as the product of probability and consequences [8], is computed as equation (1).

$$
\operatorname{Risk}\left(X_{f}\right)=\sum P_{r}(E) \operatorname{Sev}\left(E, X_{f}\right)
$$

where, $X_{f}$ is the operating state of the system before accidents; $E$ is the accident; $P_{r}$ is the probability of accident $E ; \operatorname{Sev}\left(E, X_{f}\right)$ is the severity caused by accident $E$ under the operating state $X_{f} ; \operatorname{Risk}\left(X_{f}\right)$ is the risk index.

In addition to probability and severity model of accidents occurring, the power outputs of PV system and probability model of different light intensity are also needed in the paper. The following parts will introduce these models in detail.

\subsection{Probability model of the accident}

In traditional power system reliability assessment, the failure rate of components generally is modelled as Markov state, which is averaged from historical statistical data. Reliability assessment, usually involved the long term assessment, therefore, mostly adopt the forced shutdown rate as the failure rate of the component. But for security assessment based on risk theory, as its short assessment cycle, time factors must be considered.

Assuming real-time failure rate of the component as $\lambda$, components' failure times obey Poisson distribution in interval $t$. According to the probability formula of Poisson distribution [9], failure rate of the component in interval $t$ can be derived from equation (2).

$$
P\left(F_{i}\right)=1-e^{-\lambda_{i}}
$$

where, $F_{i}$ is the failure state of components; $\lambda_{i}$ is the failure rate of components.

Assuming that components are independent from each other, fault probability of the system caused by a component fault is computed as equation (3).

$$
\begin{aligned}
P\left(E_{i}\right) & =P\left(F_{1} \cap F_{2} \cdots F_{i-1} \cap F_{i} \cap F_{i+1} \cdots F_{N_{c}}\right) \\
& =P\left(F_{i}\right) \prod_{j \neq i} P\left(F_{j}\right) \\
& =\left(1-e^{-\lambda_{i}}\right) e^{-\sum_{j \neq i} \lambda_{j}}
\end{aligned}
$$

where $E_{i}$ is the system accident, $F_{j}$ is the normal state of components. 


\subsection{Severity function of the accident}

The fundamental principles of severity functions defined in risk assessment [10]: (1) not involved in operation process after failures occur; (2) easier for the dispatcher to understand; (3) associated with deterministic criteria; (4) the expression should be intuitive and concise; (5) reflect the characteristics of different problems; (6) reflect the severity of the components. Based on these principles, a series of simple linear functions are designed to characterize the severity of power flow overload, low voltage and etc. in document [11].The application of severity function will be introduced in the following part.

\subsubsection{Severity of node low voltage}

For each node in the distribution system, according to the degree of exceeding voltage, the severity function of low voltage is defined. The node low voltage severity function is shown in Fig. 1. Assuming the limit of low voltage as 0.95 , define the severity as equation (4). Where, $V$ is the voltage magnitude.

$$
\operatorname{Sev}^{l v}(V)= \begin{cases}\frac{1-V}{1-0.95}, & V \leq 1.0 \\ 0 & , \quad V>1.0\end{cases}
$$

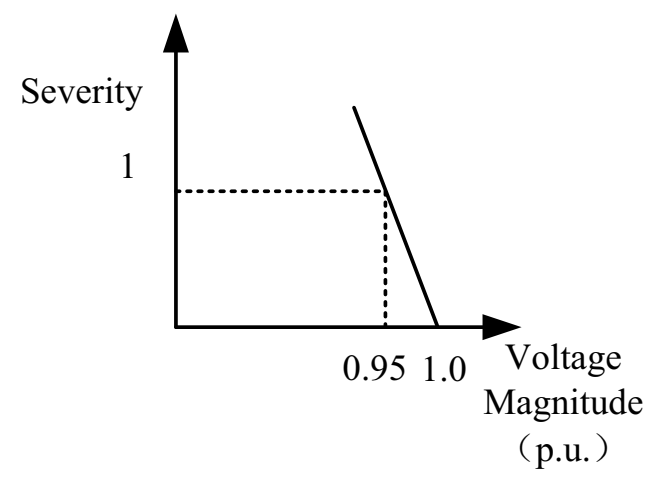

Figure 1. Node low voltage severity function

From Fig. 1, we can see that the node low voltage severity is 1 when the node voltage is 0.95 ; the severity is between 0 and 1 when the node voltage is in the interval $(0.95,1.0)$ and the severity increases as the node voltage decreases; the severity is over 1 when the node voltage is lower than 0.95 .

\subsubsection{Severity of line overload}

For each line in distribution system, assuming the limit of $\mathrm{L}$ is 0.8 , the overload severity function is defined as equation (5). Where, $\mathrm{L}$ is the ratio of the real line power and rated line power.

$$
\operatorname{Sev}^{o l}(L)= \begin{cases}1-\frac{1-L}{1-0.8}, & L \geq 0.8 \\ 0 \quad, & L<0.8\end{cases}
$$




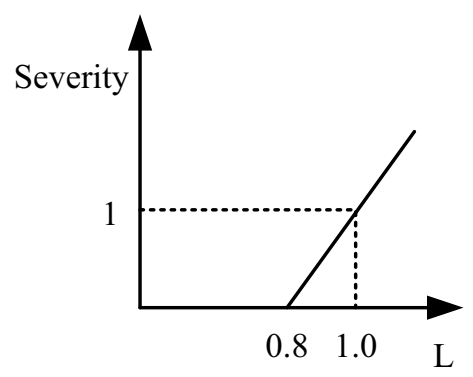

Figure 2. Line overload severity function

It is shown in Fig. 2 that the line overload severity is 0 when $\mathrm{L}$ is lower than 0.8 ; the severity is between 0 and 1 when $\mathrm{L}$ is in the interval $(0.8,1.0)$ and the severity increases as $\mathrm{L}$ increases; the severity is higher than 1 when $\mathrm{L}$ is higher than 1.0 .

\subsection{Output model of PV power}

The output of photovoltaic power generation system is closely related to the light intensity. The output model of photovoltaic system under varying light intensity is described as equation (6) [12] and the relation between light intensity and output of PV power is shown in Figure 3. With the increasing of the light intensity, the output curve is divided into three sections. In the first two sections, the outputs of PV system keep increasing. When the light intensity reaches some degree, the outputs stay constant.

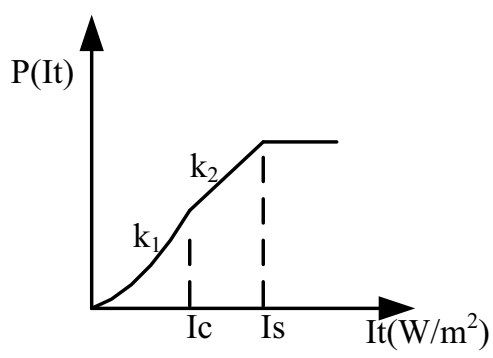

Figure 3. PV System Power Output Curve

$$
P\left(I_{t}\right)= \begin{cases}\frac{P_{r}}{I_{s} I_{c}} I_{t}^{2} & 0 \leq I_{t} \leq I_{c} \\ \frac{P_{r}}{I_{s}} I_{t} & I_{c} \leq I_{t} \leq I_{s} \\ P_{r} & I_{t} \geq I_{s}\end{cases}
$$

where $P\left(I_{t}\right)$ is photovoltaic system power output; $I_{s}$ is the standard light intensity, $I_{s}=1000 \mathrm{~W} / \mathrm{m}^{2}$; $I_{c}$ is the light intensity when the photoelectric conversion efficiency reaches maximum, $I_{c}=150 \mathrm{~W} / \mathrm{m}^{2} ; P_{r}$ is the rated capacity of photovoltaic power generation system. 


\subsection{Light intensity probability model}

The year average light intensity is used instead of the real light intensity to reduce the computational complexity. Light intensity value and the probability in this paper are referred to statistical data in document [13] in which light intensity is averagely divided into 12 groups from $0 \mathrm{~W} / \mathrm{m}^{2}$ to $1100 \mathrm{~W} / \mathrm{m}^{2}$. Table 1 shows the different light intensity and its corresponding probability.

Table 1. Power Output and Probability of PV

\begin{tabular}{|c|c|c|}
\hline $\begin{array}{c}\text { Light intensity } \\
/ \mathbf{W} \mathbf{m}^{-2}\end{array}$ & $\begin{array}{c}\text { Output/ } \\
\text { MW }\end{array}$ & $\begin{array}{c}\text { Probability for light } \\
\text { intensity }\end{array}$ \\
\hline 0 & 0 & 0.55017 \\
\hline 100 & 0.4 & 0.11519 \\
\hline 200 & 1.2 & 0.06532 \\
\hline 300 & 1.8 & 0.05290 \\
\hline 400 & 2.4 & 0.04636 \\
\hline 500 & 3.0 & 0.04479 \\
\hline 600 & 3.6 & 0.03930 \\
\hline 700 & 4.2 & 0.03355 \\
\hline 800 & 4.8 & 0.02756 \\
\hline 900 & 5.4 & 0.01933 \\
\hline 1000 & 6.0 & 0.00537 \\
\hline 1100 & 6.0 & 0.00014 \\
\hline
\end{tabular}

\section{Definition of Risk Indices}

Considering the randomness of photovoltaic power, appropriate correction is made to the risk index of node low voltage and line overload. Define the node low voltage risk index as equation (7) and line overload risk index as equation (8).

$$
\begin{aligned}
& R_{l v}\left(X_{f}\right)=\sum_{k=1}^{n}\left[\omega_{k} P_{r}(E) \operatorname{Sev}_{k}^{l v}\left(E, X_{f}\right)\right] \\
& R_{o l}\left(X_{f}\right)=\sum_{k=1}^{n}\left[\omega_{k} P_{r}(E) \operatorname{Sev}_{k}^{o l}\left(E, X_{f}\right)\right]
\end{aligned}
$$

where, $n$ is the total of light intensity groups; $\omega_{k}$ is the probability of group $k$ for light intensity; $\operatorname{Sev}_{k}^{l v}\left(E, X_{f}\right)$ is node low voltage severity of $\operatorname{group}_{k} ; \operatorname{Sev}_{k}^{o l}\left(E, X_{f}\right)$ is line overload severity of group $k$.

\section{Case Study}

To verify the feasibility of indices introduced, IEEE three-feeder distribution system is applied in this paper. Table 2 shows the branch attributes of the distribution system, referring to document [7] for other specific parameters. The capacity of PV power is set as $6 \mathrm{MW}$. The topology diagram of the distribution network is shown in Figure 4. 


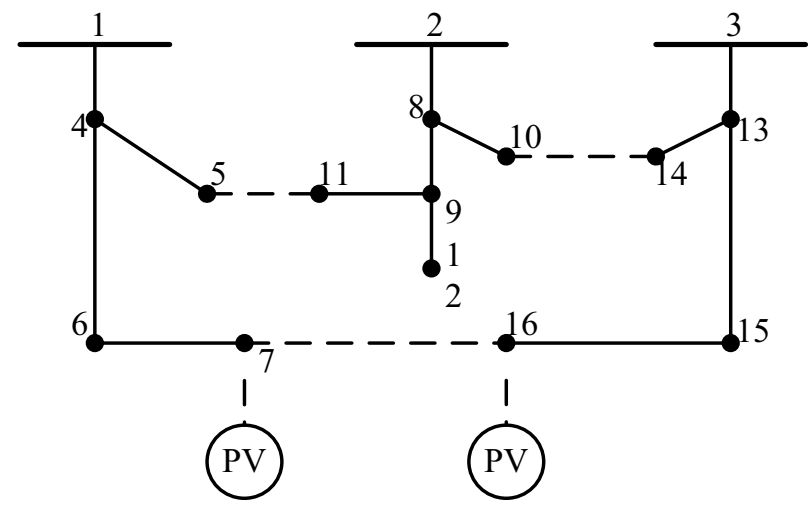

Figure 4. EEE Three-feeder System

Table 2. Branch attributes

\begin{tabular}{|c|c|c|c|}
\hline branch & $\begin{array}{c}\text { Length } \\
\text { /km }\end{array}$ & $\begin{array}{c}\text { Failure rate } \\
\mathbf{\%}\end{array}$ & $\begin{array}{c}\text { Rated current } \\
\mathbf{/ k A}\end{array}$ \\
\hline $1-4$ & 1 & 0.2 & 0.8 \\
\hline $4-5$ & 1 & 0.027 & 2.2 \\
\hline $4-6$ & 1 & 0.027 & 2.2 \\
\hline $6-7$ & 1 & 0.2 & 0.8 \\
\hline $2-8$ & 1 & 0.027 & 2.2 \\
\hline $8-9$ & 1 & 0.027 & 2.2 \\
\hline $8-10$ & 1 & 0.027 & 2.2 \\
\hline $9-11$ & 1 & 0.027 & 2.2 \\
\hline $9-12$ & 1 & 0.027 & 2.2 \\
\hline $3-13$ & 1 & 0.2 & 0.8 \\
\hline $13-14$ & 1 & 0.027 & 2.2 \\
\hline $13-15$ & 1 & 0.2 & 0.8 \\
\hline $15-16$ & 1 & 0.2 & 0.8 \\
\hline
\end{tabular}

Two cases are proposed to achieve risk based security assessment on distribution network: (1) no access of PV power; (2) accessing PV power at node 7 and node 16 . When disconnecting line 1-4, 2-8, $3-13$, there are two transfer solutions. To reduce the complexity of calculation, for these three lines, choose one transfer solution respectively by connecting switch 5-11, $5-11,10-14$.

Case (1): no access of PV power.

The test results are shown in table 3. It can be seen that the line overload risk is the highest when the line 1-4 is disconnected. This is mainly due to that the line 1-4 is directly connected to the substation and load supplied by substation 1 has to be supplied by substation 2 and 3 when line 1-4 is disconnected and the failure rate of the line1-4 is higher than other lines. For node low voltage risk, we can see that when any of line 1-4, 6-7, 3-13, 13-15 and 15-16 is disconnected the risk is much higher which is also due to the higher failure rate of these branches shown in Table 2.

Table 3. Results without PV power

\begin{tabular}{|c|c|c|}
\hline $\begin{array}{c}\text { Failure } \\
\text { line }\end{array}$ & $\begin{array}{c}\text { Node low voltage } \\
\text { Risk index }\end{array}$ & $\begin{array}{c}\text { Line overload } \\
\text { Risk index }\end{array}$ \\
\hline $1-4$ & 0.1119 & 0.04115 \\
\hline $4-5$ & 0.004443 & 0.001491 \\
\hline $4-6$ & 0.005292 & 0.01064 \\
\hline $6-7$ & 0.029745 & 0.02748 \\
\hline $2-8$ & 0.008132 & 0.01653 \\
\hline
\end{tabular}




\begin{tabular}{|c|c|c|}
\hline $\begin{array}{c}\text { Failure } \\
\text { line }\end{array}$ & $\begin{array}{c}\text { Node low voltage } \\
\text { Risk index }\end{array}$ & $\begin{array}{c}\text { Line overload } \\
\text { Risk index }\end{array}$ \\
\hline $8-9$ & 0.005089 & 0.01141 \\
\hline $8-10$ & 0.003675 & 0.003527 \\
\hline $9-11$ & 0.003516 & 0.004181 \\
\hline $9-12$ & 0.002695 & 0.003025 \\
\hline $3-13$ & 0.051219 & 0.02304 \\
\hline $13-14$ & 0.003988 & 0.002899 \\
\hline $13-15$ & 0.037013 & 0.05478 \\
\hline $15-16$ & 0.03116 & 0.04054 \\
\hline
\end{tabular}

Case (2): accessing PV power at node 7 and node 16.

The test results are shown in table 4. From table 4, it's clearly shown that the risk of the distribution system tends to be decreasing. Though the line overload risk is still high when disconnecting line 1-4, it has been reduced by accessing PV at node 7 and node 16 which is because the access of PV can help supply part of load on feeder 1. Also, we can see that accessing PV power at the end of the line, in some degree, can help reduce node low voltage risk.

Table 4. Results with PV generation at node 7

\begin{tabular}{|c|c|c|}
\hline $\begin{array}{c}\text { Failure } \\
\text { line }\end{array}$ & $\begin{array}{c}\text { Node low voltage } \\
\text { Risk index }\end{array}$ & $\begin{array}{c}\text { Line overload } \\
\text { Risk index }\end{array}$ \\
\hline $1-4$ & 0.09327 & 0.03015 \\
\hline $4-5$ & 0.003323 & 0.001287 \\
\hline $4-6$ & 0.004167 & 0.009127 \\
\hline $6-7$ & 0.027364 & 0.02634 \\
\hline $2-8$ & 0.005194 & 0.008231 \\
\hline $8-9$ & 0.004569 & 0.009234 \\
\hline $8-10$ & 0.003562 & 0.002865 \\
\hline $9-11$ & 0.002865 & 0.003259 \\
\hline $9-12$ & 0.002573 & 0.002914 \\
\hline $3-13$ & 0.04931 & 0.02086 \\
\hline $13-14$ & 0.003564 & 0.002682 \\
\hline $13-15$ & 0.03259 & 0.04383 \\
\hline $15-16$ & 0.02768 & 0.03928 \\
\hline
\end{tabular}

By comparing Table 3 and Table 4, when accessing PV power at node 7 and node 16, changes of risk indices tend to be consistent. It is shown that the access of PV power can effectively reduce the risk of the system regardless of load changes although the randomness of PV power is involved. Through table 3 and table 4, it can be seen that not only the consequences of accidents but also probability of accidents occurring is worth to be considered in the security assessment.

\section{Conclusions}

In this paper, by adding uncertain factors to risk indices, the randomness of PV power outputs reflected. Considering the flexibility of distribution network structure after failures occur, the security based on risk theory of distribution network is assessed. Test results show that in the end of the branch accessing PV power supply can effectively reduce the risk of system. However, effects caused by different capacity of PV power, different access site and time-varying characteristics of load haven't been analyzed. If these influence factors are appropriately considered, the assessment will be more reasonable. 


\section{References}

1. C.Q. Liu, Y. Zhang, "Distribution Network Reliability Considering Distribution Generation", Automation of Electric power systems, 31(22), pp. 46-49,(2007).

2. Y.Y. Yang, J.Y. Yang, Z. Huang. " Risk Assessment System of Distribution Network and Its Application”, Modern Electric Power, 28(4), pp. 20-23, (2011).

3. W.P. Zhou. " Risk Analysis of Distributed Photovoltaic Power Network"[D], North China Electric Power University, (2014).

4. Y. $\mathrm{Xu}, \mathrm{K}$. Wang, B. Chen, "Reliability and Risk Assessment Techniques for Distribution Networks with Distributed generations", Proceedings of the CSU-EPSA, 25(4), pp. 117$121,(2013)$.

5. Z.Z. Guo, W. Liu. "Research on Security Indices of Distribution Networks", Proceedings of the CSEE, 23(8), pp. 85-90, (2003).

6. T.H. Wang, P.Y. Wang, M.T. Fan. "Optimal Feeder Automation Planning Using Binary Programming", Proceedings of the CSEE, 20(5), pp. 54-58, (2000).

7. R.X. Liu, J.H. Zhang, D. Wu. " Research on Static Security Index of Distribution Network Based on Risk Theory", Power System Protection and Control, 39(15), pp. 89-95, (2011).

8. J.D. McCalley, V. Vittal, N. Abi-Samra, "An Overview of Risk Based Security Assessment". Edmonton: Power engineering Society Summer Meeting,1999.

9. H. Wan, J.D. McCalley, V. Vittal, "Risk Based Voltage Security Assessment", IEEE Transactions on Power Systems, 15(4), pp. 1247-1254, (2000).

10. M. Ni, J.D. Mccalley, V. Vittal, et al, "Online Risk-Based Security Assessment", Power Engineering Review IEEE, 22(1), pp. 258 - 265, (2002).

11. J.D. McCalley, B.L. Agrawal, V. Vittal, et al, "A Risk-based Security Index for Determining Operating Limits in Stability-limited Electric Power System", IEEE Transaction on power systems, 12(3), pp. 1210-1219, (1997).

12. J. Park, L. Wu, J. Choi, et al. "A Probabilistic Reliability Evaluation of a Power System Including Solar/Photovoltaic cell generator". Power \& Energy Society General Meeting, (2009).

13. Cha, Seung Tea, et al. "Reliability Evaluation of Distribution System Connected Photovoltaic Generation Considering Weather Effects", Probabilistic Methods Applied to Power Systems, 2004 International Conference on IEEE, pp. 451 - 456, (2004). 